\title{
The Leading Role of Chinese Discourse in Global Context: The Variation Theory of Comparative Literature
}

\author{
Miaomiao Wang ${ }^{1}$ \\ ${ }^{1}$ North China Electric Power University, Beijing, China \\ Correspondence: Miaomiao Wang, North China Electric Power University, Beijing, 102206, China. E-mail: \\ pauline@ncepu.edu.cn
}

Received: April 6, 2020 Accepted: May 5, 2020 Online Published: May 27, 2020

doi:10.5539/ells.v10n2p66 URL: https://doi.org/10.5539/ells.v10n2p66

\begin{abstract}
Chinese scholar Cao Shunqing devoted himself to the construction of Chinese Comparative Literature discourse system and successfully established a new discourse of the variation theory of comparative literature in the eponymous book. This is the latest practice of President of the People's Republic of China Xi Jinping's advocation to construct Chinese discourse theories. The variation theory of comparative literature is a significant concept that has been accepted and applied by the international society, in which its effects have conducted major contributions to the development of discourse system and literature theory with Chinese characteristics. And it has positively pushed the construction of Chinese soft power in the global context. As a new concept, a new field, and a new statement, the emergence of the variation theory of comparative literature has led to heated discussions and researches at the international academic level and received great feedbacks from various scholars, both national and international.
\end{abstract}

Keywords: the variation theory, comparative literature, Chinese discourse, global context

\section{Introduction}

In terms of the ways to construct Chinese Discourse, President Xi Jinping of People's Republic of China suggests that, "(we need to) give a role to the philosophy and social science and focus on the construction of Discourse System"; "(we need to) extract identified concepts and establish the new concepts, new fields and new statements that can be widely understood and received by the international society. To do it, we need to start with discipline constructions, in which every discipline has to create its own theories and concepts." (Xi, 2016; unless indicated otherwise, all translations are by Wang) Chinese scholar, Professor Cao Shunqing's Variation Theory of Comparative Literature is the latest practice of President Xi's advocation of "Construction of Discourse Theory" which established a new concept, new field and new statement that has been widely understood and accepted by international society.

With China's growing comprehensive national power and the deepening cultural communication with oversea countries, "Chinese Discourse" has not only become a focal point in academia, but also a crucial developing strategy of national humanities and social sciences. Professor Sun Shaozhen published in Guang Ming Daily that, "Twenty years ago, Professor Cao had already got his reflection that 'Chinese literature theory has lost its power" (Sun, 2017). He argued that "Chinese literature theory was an academic alogia, in the sense that we did not have our own literary theory, and without the western literary theory, we could not voice. And it was even more obvious that the weak Chinese literary theory was submerged by the strong western theory and we had essentially lost our subjectivity. Mr. Ji Xianlin suggested that, "we are as mute as fish in the literary theory field, in the sense that no one from us (the oriental countries) has created any meaningful theories in the modern and contemporary times.' This indicated that the national originality of Chinese literature theory was missing." (Sun, 2017) The Chinese President Xi truly agreed with this statement and suggests that "our philosophy and social science has quite a 'low voice' on the international level in which we are still not able to share our views freely." "Following others' steps will not help with the establishment of philosophy and social science with Chinese characteristics, nor will solve the practical problems." (Xi, 2016) Professor Sun believes that "the aim of introducing western literary theories is to digest them with our own traditional culture, to strengthen our cultural mechanism, and to talk to them equally in search for complementation and cooperation. It collaborates with $\mathrm{Mr}$. Shi Hu's perspective that the 'input theory' works for 'recreating civilization', in other words, to create the 
Chinese Literary Theory Discourse. Professor Cao believes that the key point here is the connection with traditional culture. And Qian Zhongwen has also suggested the issue of modernizing the Chinese ancient literary theory." (Sun, 2017)

According to Journey of Theories by Edward Said, a literary theory discourse varies when travelling from one country to another. And the modern Journey of Theories follows the route from west to the east, in which the east is receiving the western literary discourse. And when the western literary theory discourse reaches China, it varies on two different levels. On one hand, from the knowledge genealogy level, the western literary theory almost fully replaces the Chinese one. Contemporary Chinese academic and literary research almost copies from the west, which changes Chinese discourses and expressions into the western forms. During the new period, China largely introduced western literatures and theories, e.g., Matin Heidegger, Franz Kafka and Jurgen Habermas. Yet Chinese academia remains 'alogia' due to its rare innovation of such theories. Rather than reconstructing western theories based on the Chinese mode of discourse, we tended to imitate them. On the other hand, western theories have transformed themselves and have become sinicized. In order to achieve the sinicization of western theories and remedy the 'alogia' of the Chinese literary theory discourse, we need to combine western theories with eastern ones, select and absorb proper western literary theories and propel the development of Chinese theories. To understand this concept, avoiding domestic appropriation is key. First, faced with different cultural background and language translation, western literary theories are spontaneously endowed with certain Chinese characters, for a recreation progress that includes absorption, selection, filtration and misreading, which is a common phenomenon when one culture travels to another. Second, the western literary theories need to combine with Chinese traditional culture, academic rules and discourse customs to achieve its sinicization. The introduction of western theories has caused the alogia. Therefore, it is important to rethink the previous misreading of traditional culture and to re-examine the Chinese traditional classics. Only by following these frameworks will Chinese literary theories develop fully, elucidate the academic issues, and exhibit its own prestige when conducting equal dialogue with the western ones. And this is indeed the creativity of the discourse system. Therefore, in order to reconstruct the modernity in the discourse of Chinese literary theory, it is necessary to hold fast to its own discourse system and take reference from the core of western ones, and thus to avoid being determined by western literary theories and then to achieve a good combination of the national and international mechanisms, and to achieve the modern transformation of traditional literary theories.

Then how to promote today's construction of Chinese discourse requires great effort to connect ourselves to traditional culture so that we can link Chinese traditional discourse to the modern one. We will also practice the methods of discourse construction put forward by President Xi Jinping. The method is to refine the iconic concept of the subject and construct a new concept that can be easily understood and accepted by national society. As a comparatist, Professor Cao Shunqing began with the construction of the theoretical discourse system of Chinese comparative literature and successfully established a new concept of variation theory of comparative literature, which is not only an important part of humanities, but also with great relevance for both the East and the West. Given the current pursuit of the Chinese dream of national rejuvenation and the increasing of international communication between China and the West, the construction of the theoretical discourse of Chinese comparative literature must be a task of both great significance and challenges. Since the world has entered a new century, communication between China and the West shows multi-layered and wide-ranging patterns, with tremendous change in China's technological, economic, and cultural capabilities and situations, many fields will require the construction of Chinese discourse, not only the construction of the Chinese discourse. The construction of theoretical discourse of Chinese comparative literature has its significance in discipline and contributes to the promotion of China's soft power. It also has a national characteristic and its own quality, as well as an international perspective and a global mindset world. This is a principle that must be upheld when Chinese School of comparative literature constructs its own disciplinary theoretical discourse. To construct a theoretical discourse of comparative literature requires us to demonstrate a Chinese character which includes four aspects. First is to resolute the current crisis in comparative literature. Second is to learn Chinese traditional culture and wisdom. Third is to make the character itself to embrace global mind and far reaching vision accepted by the world. Forth is to improve the Chinese character and diffuse across the globe, to make it a more universal theory and an iconic concept accepted by the world. Thus, the theoretical discourse system of Chinese comparative literature can focus on the present, guide the international academia to carry out research and discussion, stand on for a long time, continue to progress, and achieve an international influence. As President Xi Jinping pointed out that: "if we intend to exert the power of philosophy and social science, we must focus on the enhancement of the construction of discourse system." (Xi, 2017) But how to construct Chinese discourse? President Xi Jinping thinks that "we will be adept in refining pre-existing concepts and establishing new concepts, new categories, and new expressions that can easily be accepted and understood by international 
society. It requires us to begin with the construction of disciplines. Each discipline requires to establish a systematic disciplinary theory and concept." (Xi, 2017) This requires us to discipline ourselves beyond the existing western ones, to promote Chinese theoretical discourses to a global level, and then to be recognized by the world with Chinese characters, when we construct the theoretical discourse of the discipline of Chinese comparative literature.

In 2005, at the Eighth Congress of the Chinese Comparative Literature Association, Professor Cao initially put forward the concept of the variation theory of comparative literature. And in 2006, he published a paper entitled with "The Research Field of Literary Variation in Comparative Literature" (Cao, 2006), in which he formally expounded the variation theory of comparative literature. In 2014, Professor Cao's English book The Variation Theory of Comparative Literature was published by the Springer Press, one of the foremost publishers in the world. And it was published in New York, London and Heidelberg at the same time. The Variation Theory of Comparative Literature systematically depicted the characteristics and limitations of the paradigm which was applied in comparative literature by both the French School and American School. And a new disciplinary theory of Chinese comparative literature was first put forward in English - the universal language. The Variation Theory of Comparative Literature presents its theoretical discourse and research methods filled with Chinese characteristics to the world and suggests a feasible direction for further development of comparative literature. The variation theory of comparative literature has not only guaranteed the scientific and legal boundary of the discipline, but also greatly expanded the methodologies and perspectives. It takes variability as an important factor with which to study the comparability of comparative literature, which has exposed the limitation of common modes of thinking and studying which were seeking common ground. And the variation theory of comparative literature embodies the characteristics of the methodology from the Chinese School of comparative literature and also brings new vitality into the comparative literature study in the world. Moreover, it has expanded the academia of international comparative literature and has led the academia to do further researches on it.

The variation theory of comparative literature has filled a huge blank of "influence study" of French school and "parallel study" of American school. It pushed forward the theory of comparative literature to a brand-new stage, which emphasizes heterogeneity and variability. In particular, it has started fresh field on cross-civilization variation studies. Therefore, through the entire development in history of human literature, the collision between different civilizations undoubtedly spurred emergence of a new literary characters, and it also illustrated the heterogeneity and variability of different civilizations, of which the comparison, communication and integration will be a higher prospect of human cultural exchanges. "The variation theory of comparative literature is the study on variations of the literary phenomena of different countries with or without factual contact as well as the comparative study on the heterogeneity and variability of different literary expressions in the same subject area so as to achieve the goal of exploring the patterns of intrinsic differences and variability. It focuses on the recognition of heterogeneity of traditional genealogy, and established heterogeneity as the basis of the comparability. It mainly has five parts: the variation theory in cross-country context, the variation theory in cross-language context, cross-cultural variation theory, cross-civilization variation theory, and foreignization of literature." (Cao 2014) Variation Theory of Comparative Literature is based on the communication of literature from different countries and different civilizations. The variation theory focuses on variability and literariness.

In terms of the construction of theoretical disciplinary discourse, the variation theory of comparative literature made a revolutionary change of Chinese comparative literature in the basic concept. When the discipline of Comparative Literature was established, it aimed at seeking for the similarities of literature in different countries, disciplines and civilizations at the beginning. But its greater value is to seek the variation of literature when transmitted in different countries, as well as the heterogeneity among different civilizations. It is the Chinese scholar who has put forward the variation theory of comparative literature, which is based on heterogeneity and variability. It requires studies on comparability of comparative literature and emphasizes commonality and heterogeneity. The study of variation theory can not only show Chinese characteristics, but also have the world vision. It can not only promote the theoretical originality, but also save the discipline crisis, break the western stereotypes, and meet the international needs. The research of variation theory meets the demand in current academic and discourse needs. This theory not only solves the problem of comparability of the heterogeneity of comparative literature, but also solves the problem of variation in the influence of literature, which is beneficial to excavate the variability and innovation of literary relations among different countries, disciplines, cultures and civilizations. The variation theory of comparative literature introduces a new Chinese discourse to the world, promotes the communication, integration and innovation of culture and literature in the worldwide and builds a new pattern of "harmony in diversity" in the global academic discourse. As the construction of social scientific 
discourse with Chinese characteristics, the variation theory of comparative literature has attracted great attention and praise from international academia, including comparatists from the United States, France, the Netherlands, Belgium, Denmark, Spain and other countries.

\section{Heterogeneity as the Basis of Comparability in Comparative Literature}

The study of comparative literature pays attention to the common law of the implied literary phenomena, and to the variation of literature in different countries in the process of communication and dissemination, as well as to the heterogeneous factors among different civilizations. The basis of comparability is the variation of literature. Comparative literature pursues both commonality and heterogeneity, in order to construct a harmony in the exchange and integration of world literature.

Sven Erik Larsen, fellow of the Academia Europaea, Professor Emeritus, University of Aarhus, Denmark published a review article on Professor Cao's book The Variation Theory of Comparative Literature in Orbis Litterarum. In his article, Professor Larsen mentioned: "Shunqing Cao, himself a Professor of comparative literature in Beijing and Chengdu, shows an extraordinary erudition with respect to the long European tradition in comparative literature since its inception around 1800 and a wide-ranging familiarity with the long history of Chinese meta-reflections on literature." "In line with many studies in world literature, Shunqing Cao insistently maintains a focus on the particular literariness of texts as it is perceived in different cultures, but also searches for the cross-cultural dynamics that generate any literary phenomenon, its effects and its conceptualization. Thus, the book is an invitation to enter into a dialogue with established Western comparatism. And the time is ripe for dialogue: world literature studies, translation studies, genre studies, studies of the political, studies of the posthuman, studies of digital media and literatures - all such partly overlapping research interests are cross-disciplinary and open to cross-cultural dialogues to which this volume is also an invitation." (Larsen 437) Angelica Duran, Professor of English and Comparative Literature at Purdue University, USA, takes the variation theory of comparative literature as "the Root of Literature" in her edited book Mo Yan: Nobel Prize winners and Global storytellers. She said: "In Variation Study in Western and Chinese Comparative Literature, Shunqing Cao and Miaomiao Wang outline contemporary Chinese literary and critical scholarship, addressing the practical past, present, and likely future obstacles for enacting truly multidirectional comparative cultural studies. They do this from a Chinese scholarly context and in the service of providing provisional and promising methodologies. Cao and Wang provide an overview of the introduction and development of comparative literature in China showing that, following a course of integrative processes, Chinese scholars are reconstructing existing subjects and addressing the phenomenon of variation between literatures. They apply the critical methodology that the article's lead author, Cao, has developed in recent decades in order to assess heterogeneity and variability between literatures rather than assume a literary universalism. They outline how this direction of the research can contribute to the ongoing development of comparative literature." (Duran \& Huang 13) Besides, Professor Wang Ning from Tsinghua University also mentioned the important role of the variation theory of comparative literature in practical applications in the third part of the book: "Cosmopolitanism and Internationalization of Chinese Literature". He proposes that "Literary criticism must continue to address striking national characteristics: actively, as Shunqing Cao and Miaomiao Wang demonstrate in this volume Variation Study in Western and Chinese Comparative Literature, as well as inertly in response to reader reception, which of course is dependent on translations into languages available to different sets of readers." (Wang 173)

Additionally, in a review article entitled "Variation Theory and Comparative Literature: A Book Review Article about Cao's Work, published on the Journal of CLCWeb: Comparative Literature and Culture, which is published by Purdue University Press, indexed by Arts and Humanities, the author says: "I believe that Cao's the variation theory of comparative literature is an important contribution to the discipline and I am suggesting this based on my understanding of the discipline's theoretical status quo in English-language scholarship" "While the long-standing bias of Orientalism still dominates, the value of Chinese culture and literature must be acknowledged and incorporated in comparative literature studies and it is here where Cao's work is timely and relevant." "I assume that Cao does not expect his western colleagues to agree with him or apply some of his theoretical notions. Instead, what I gather from my conversations with him is that he intends to attract scholarly debate with Western comparatists in the context that Chinese scholars have been doing something different from Western comparative literature scholarship. I think if this goal could be realized, Chinese scholarship in comparative literature would achieve something that eluded it until now and, more importantly, perhaps the usual situation whereby Chinese scholars simply import Western thought would at least be modified. In the past, Chinese comparatists always tried to seek homogeneity, but now they will try to seek heterogeneity and in this sense the publication of Cao's book makes a significant breakthrough in comparative literature studies not only in China, but in general." (Wang 15.6, http://docs.lib.purdue.edu/clcweb/vol15/iss6/17/) 
Professor of University of Arizona, USA, Li Dian published an article in the Journal Cultural Studies and Literary Theory, entitled with World Literature and Translation/Reading as an Exchange of Alterity, in which he began with the story of Goethe's invention of the concept of world literature while reading a Chinese novel. And he put forward that "The varying strategies in translation deal with alterity, thus invigorate the discourse of sameness and difference in the concept of world literature." $(\mathrm{Li}, 1)$ " $\ldots$ and in critical positions associated with 'Variation Theory', a theory of cross-cultural literary relations that has started to have an impact with the scholarly community in the West." ( $\mathrm{Li}, 9)$

\section{Universal Disciplinary Theory and International Recognized Concept}

Variation theory of comparative literature is a universal disciplinary theory and internationally recognized concept. It enables comparative literature to transcend influence study and parallel study to a certain extent, to transcend the so-called Oriental and Western perspectives, to eliminate cultural conservatism and chauvinism, and to achieve the research goal of "world literature and general literature" in this discipline. At the same time, the theoretical discourse system of variation is also an innovation of the academic discourse system with Chinese characteristics.

Cesar Dominguez, fellow of the Academia Europea, Professor Jean Monet of Comparative Literature, University of Santiago Compostela, Spain, together with Haun Saussy, fellow of the National Academy of Sciences, Professor of Comparative Literature, University of Chicago, USA, co-authored a book which is entitled with Introducing Comparative Literature: New Trends and Applications, highly appraised Professor Cao Shunqing's the variation theory of comparative literature. Dominguez and Saussy quote lines from Professor Cao's book: "Another important contribution in the direction of an imperative comparative literature-at least as procedure-is Cao Shunqing's 2013 The Variation Theory of Comparative Literature. In this case, Cao starts by making his etic location visible. In contrast to the 'French School' and 'American School' of comparative Literature, Cao advocates a 'third-phrase theory,' namely, 'a novel and scientific mode of the Chinese school,' a 'theoretical innovation and systematization of the Chinese school by relying on our own methods'. (Variation Theory 43; emphasis added). From this etic beginning, his proposal moves forward emically by developing a 'cross-civilizational study on the heterogeneity between Chinese and Western culture' (43), which results in both the foreignization of Chinese literary theories and the signification of western literary theories." ((Dominguez \& Saussy 50) Bernard Franco, Director of the Department of Comparative Literature, University of Sorbonne, France, has repeatedly mentioned and highly praised Professor Cao's variation theory of comparative literature in his monograph La littérature comparée: Histoire, Domaines, Méthodes. He believes that the theory is an important contribution from the Chinese to global comparative literature. Douwe W. Fokkema, the former President (2005-2008) of the International Comparative Literature Association, Professor Emeritus at Utrecht University, wrote the preface for Professor Cao's book The Variation Theory of Comparative Literature. As one line goes: "Professor Shunqing Cao's book on the variation theory of comparative literature, appearing now in English, is a welcome attempt to break through the linguistic barrier that keeps most comparatists in China enclosed within their own cultural domain. Cao's book aims to open a dialogue with scholars abroad, in Europe and North and South America, India, Russia, South Africa, and the Arab world. Shunqing Cao's argument contains many pertinent observations and, where we have reason to disagree, we must express our own views so as to continue the discussion. The variation theory is an answer to the one-sided emphasis on influence studies by the former "French school" as well as to the American focus on aesthetic interpretation, inspired by New Criticism, which regrettably ignored literature in non-European languages. Our Chinese colleagues are right in seeing the restrictions of former comparative studies and are fully entitled to amend these deficiencies. However, it is important to view the rise and interaction of the various schools which Cao describes in their historical context." (Cao V) Sven Erik Larsen, fellow of the Academia Europaea, Professor Emeritus, University of Aarhus, Denmark published another article on the variation theory of comparative literature in the Journal Cultural Studies and Literary Theory, which is entitled with Various Theories-and Variation Theory. He took into the account the role of literature in the multicultural and multidimensional contact zones of globalization, and applied the variation theory into food culture, contact zone, troubled historical dichotomies, and whether variation theory used as a theory or methodology in literature studies. And he concluded that "Variation Studies will be a welcome Chinese voice sharing interests with colleagues around the multicultural world with a lot to offer-only not a complete and unique theory." (Larsen, 14)

The Variation Theory of Comparative Literature has not only attracted the attention of national and international scholars in comparative literature, but also has been recommended in various websites and bookstores in the world. Among them, the most popular one is Amazon. On the website, the reference price for a new book of the Variation Theory of Comparative Literature is \$129. And the reference information goes as the follows: 
"Introduction to the Variation Theory: An Important Breakthrough of Comparative Literature. Chapter I. Major Contributions of Influence Study and Its Weaknesses. Chapter II. Major Contributions of Parallel Study and Its Weaknesses. Chapter III. The Variation Theory on the Aspect of cross-state. Chapter IV. Cross-cultural Variation Theory. Chapter V. Cross-civilization Variation Theory." (Amazon) The other significant endorsement is from another one of world's largest academic bookstores-Blackwell Bookstore in the UK, with a reference price at $£ 101.01$, which is generally higher than the prices of similar academic books. The information on the book on the bookstore's website is as follows: "Seeing the restrictions of former studies in Comparative Literature and aiming to amend these deficiencies, the author of this book mainly discusses the major theoretical significance and academic value of the Variation Theory in the whole process of the development of Comparative Literature in the world. In this book, modern Chinese study of comparative literature is put in a historical context with regards to the theoretical issue of the discipline in China through the entire 20th century. It is not only the important phenomenon in literary communication, but also the most valuable research object in Comparative Literature. Still, it will be an important path to cultural innovation. The Variation Theory may make up the major flaws of theories by both French school and the American School since it focuses on heterogeneity and variability in cross-cultural literary events, especially the ones of inter-civilization which will be a new course for comparative literature. In this sense, the proposed book attempts to challenge the myth of monolithic theories of comparative literature, trying to construct an alternative theory of the discipline." (Blackwell)

\section{Chinese Discourse of Comparative Literature in Global Communication}

In the global context, the communication with Chinese Discourse to the world requires to surpass the existing western standards in constructing Chinese theoretical discourse in comparative literature, which is to meet the global criteria, and be recognized by the world at the same time without losing its individuality. The variation theory of comparative literature is a kind of universal disciplinary theory. To some extent, it makes comparative literature transcend influence study and parallel study, and the so-called oriental and western perspectives, remove cultural conservatism and chauvinism, and realize the research goal of "world literature and general literature". The theoretical discourse system of variability is also the academic discourse system with Chinese characteristics. And there are quite a lot of feedbacks via emails from international scholars.

David Damrosch, Ernest Bernbaum Professor of Comparative Literature, Harvard University, pays particular attention to the book. He wrote: "It (The Variation Theory of Comparative Literature) represents a most welcome outreach to give a Chinese perspective in English. Your emphasis on variation provides a very useful perspective that helps go beyond the simplistic Huntington-style clash of cultures on the one hand or universalizing homogenization on the other." In addition, Professor David Damrosch also commented on the book from the perspective of the French school and American school, focusing on cross-cultural variation and cultural tradition. Hans Bertens, former President of the International Comparative Literature Association (2013-2016), Professor Emeritus at Utrecht University, the Netherlands, has conducted an in-depth reading and overall evaluation of from an interdisciplinary of the book. He said he enjoyed reading the book very much. Although his field of study is mainly post-war literature, and though he is not well versed in some of the contents of the book, he thinks the arguments and profound contents of the book are well worth reading. And he also shared his reading report on the book Introducing Comparative Literature: New Trends and Applications. He said that "I very much enjoyed your book. Since my focus is on post-World War II literature, I am obviously not an expert in much of the material that you cover, but your arguments and your erudition made reading your study more than worthwhile." And he continued that "By the way, Cesar Dominguez, Haun Saussy, and Dario Villanueva, in their recent Introducing Comparative Literature: New Trends and Applications call your work an 'important contribution in the direction of an imperative comparative literature." Theo D'haen, fellow of the Academia Europaea, chief editor of European Review, Professor of English and comparative literature at University of Leuven, also commented on The Variation Theory of Comparative Literature that: "I am already sure, though, that Cao's book will mark an important stage in the development of comparative literature away from a predominantly Western-centered approach to a more universal one." Subha Chakraborty Dasgupta, Professor of comparative literature at Jadavpur University, India, shared her excitement and reading experience of the book. She wrote in an email: "The idea of Variation projected in Professor Cao Shunqing's book The Variation Theory of Comparative Literature is important to all practicing comparatists both inside and outside the American and Western world. The practice of our discipline is premised upon the existence of an equal ground of cultural communication and the book alerts us to the fact that because of historical circumstances today, the ground reality is that the ecological balance of world culture has been destroyed in the context of grids of thought and theoretical formulations. All concerned need to work together to rectify the situation both for the sake of the discipline and for larger civilizational goals." She added, "We do need more in-depth cross-cultural conversation 
and Professor Cao Shunqing's book asks us to make a new beginning." In addition to his published book Introducing Comparative Literature: New Trends and Applications, which greatly affirmed the study of variation in comparative literature, Haun Saussy, member of the US National Academy of Sciences, Professor of comparative literature at the University of Chicago, USA, sent a special email to express his "great interest" in the book. Besides, Gayatri Chakravorty Spivak, Professor of Comparative Literature at Columbia University, USA, and other internationally renowned comparatists also wrote to share their reading experiences and high opinions of the book.

Apparently, the variation theory of comparative literature has become an iconic discourse of international comparative literature with influence internationally. As a Chinese discourse in comparative literature, the variation theory has attracted extensive attention and considerable acclaims, truly realizing Mr. Xi's proposition of refining a pre-existing concept and constructing a new concept, new category, and new expression that can easily be accepted and understood by national academia to provoke new research and allow Chinese academic discourse to generate world influence.

At the XXII Congress of International Comparative Literature Association, with the theme of Literature of the World and the Future of Comparative Literature, took place at the University of Macau, 2019, which was preceded by the ICLA Executive Council Meeting and International Forum. At the opening ceremony, Theo D' haen, fellow of the Academia Europaea, chief editor of European Review, Professor of English and comparative literature at University of Leuven, highly recommended the book The Variation Theory of Comparative Literature to the public, as it was taken as a masterpiece of the rise of Chinese comparative literature studies or even Asian comparative literature studies. And then at the panel of variation theory of comparative literature, which aroused much attention among the other over 30 panels, Professor D'Haen, gave a presentation on The Variation Theory of Comparative Literature from a World Literature Perspective. He expounded the general significance of the variation theory of comparative literature from a perspective of world literature, and he also interpreted the application of this theory in Epic in the western literature, to reply the variation phenomenon in Wang Guowei's tragic consciousness in China. And he took the show and the reception of the English version of the German play Mother Curge's Cucumber as an example to show the linguistic variation still exists in literary translation, across nations, across languages, and across cultures. And he claimed that "Western literary historical criticisms are coming through, that is another variation that I think of comparative literature. That is said that we should not try to look at Chinese literature, or African literature , or Japanese literature, or even Indian literature with western concepts, but that we should look at them with their own concepts, follow their own evolution, and their own development. And only at the end from a comparative point of view, not try to see that they are efficient and that they are lucky, or that they are not as good as western criticism or literary theory. They simply see them as different, and then to try to not evaluate them but to use them within their own complex, and then perhaps also can try and see what they can tell us about western literature, instead of all what the other ways around. But I think that's own your point comes into being now, but I think certainly that is part of the future, the book Variation Theory of comparative literature can help us in the region." (D'haen, presentation) Besides, the book Variation Theory of Comparative Literature has been paid close attention to by the OCCT: Oxford Comparative Criticism and Translation, and its Journal Oxford Comparative Criticism and Translation Review, which has been advertising of calling for book reviews of it from comparatists and scholars all over the world.

\section{Conclusion}

The variation theory of comparative literature has been a symbolic concept accepted by international academia. It demonstrates great innovation and marks a breakthrough of Chinese discourse in comparative literature. Its worldwide influence is of great contribution and guiding significance to the development of literary discourse with Chinese characteristics. And it also plays a positive role in promoting the construction of Chinese cultural soft power in the global context. The core of comparative literature variability is to focus on heterogeneity and variability in cross-cultural studies. This theoretical discourse can not only solve the problem of comparability of the heterogeneity in comparative literature, but also can be applied to the interpretation of variation in literary influence relations, as well as the study of variability and creativity in different countries, disciplines, cultures and civilizations. Meanwhile, the variation theory of comparative literature has become a disciplinary theory and methodology that represents the Chinese school in the field of comparative literature, which is widely used in the field of literature, culture, art, and communication. It is with global and universal significance, as a new concept, new category and new expression that can be easily understood and accepted by the international community. This has led to new study in world academia. Besides, the discourse system of the variation theory of comparative literature has also promoted the innovation and development of Chinese literary theoretical discourse, to achieve equal dialogues globally and set up a harmonious society of "harmony in diversity". It is 
with global and universal significance, for constructing a systematic theoretical discourse of Chinese comparative literature, for the healthy development of Chinese and international comparative literature, for the whole construction of "Chinese discourse" in the contemporary era, for the realization of the great rejuvenation of the Chinese nation, though the construction of Chinese discourse system, as an important strategy for the development of Chinese culture and the Chinese culture towards the world, is still a significant challenge.

\section{Acknowledgments}

Research for the above article has been supported by Project of Humanities and Social Sciences, Ministry of Education of the People's Republic of China, A Study of Variation and Communication of Chinese Culture and Image in US-American Newspapers in the New Media age, Project No. 19YJCZH162; and Fundamental Research Funds for the Central Universities, Project No. 2020MS056.

\section{References}

Bernard, F. (2016). La Litterature Comparee: Histoire, Domaines, Methodes. Armand Clin. https://doi.org/10.3917/arco.franc.2016.01

Cao, S. Q. (2006). A Course in Comparative Literature. Beijing: Higher Education Press.

Cao, S. Q. (2014a). The Variation Theory of Comparative Literature. Heidelberg: Springer Press.

Cao, S. Q. (2014b). An introduction to Comparative Literature. Beijing: Higher Education Press.

Cao, S. Q., \& Li, W. T. (2006). The Research Field of Literary Variation in Comparative Literature. Fudan Journal, 1, 79-83.

Cao, S. Q., \& Wang, M. M. (2014). Variation Study in Western and Chinese Comparative Literature. In A. Duran \& Y. H. Huang (Eds.), Mo Yan in Context: Nobel Laureate and Global Storyteller (pp. 183-193). West Lafayette: Purdue UP.

Cesar, D., Haun, S., \& Dario, V. (2015). Introducing Comparative literature: New Trends and Applications (p. 50). London and New York: Routledge.

Duran, A., \& Huang, Y. H. (Eds.) (2014). Mo Yan in context: Nobel laureate and global storyteller (p. 13). Purdue University Press. https://doi.org/10.26530/OAPEN_626983

Li, D. (2018). World Literature and Translation/Reading as an Exchange of Alterity. Cultural Studies and Literary Theory (Sum), 38.

Li, Q. L. (1997). Construction of Discourse and Inheritance of Cultural Spirit. Seeking Truth, 4.

Sun, S. Z. (2017). Treating Academic Aphasia and establishing New Discourse of Chinese Literary Theory. Guangming Daily, 7.

Svend, E. L. (2015). Book Review: Cao Shunqing. The Variation Theory of Comparative Literature. Orbis Litterarum, 70(5), 437. https://doi.org/10.1111/oli.12098

Svend, E. L. (2018). Various Theories-and Variation Theory. Cultural Studies and Literary Theory (Sum), 38.

Theo, D. (2019). The Variation Theory of Comparative Literature from a World Comparative Literature Perspective. Speech at The XXII Congress of ICLA, Macau, 2019.

Wang, M. M. (2013). Comparative Literature in Chinese: A Survey of Books Published 2000-2013. CLCWeb: Comparative Literature and Culture, 15(6). https://doi.org/10.7771/1481-4374.2370

Wang, N. (2013). Variation Theory and Comparative Literature: A Book Review Article about Cao's Work. CLCWeb: Comparative Literature and Culture, 15(6). https://doi.org/10.7771/1481-4374.2371

Wang, N. (2014). Cosmopolitanism and the Internationalization of Chinese Literature. In A. Duran \& Y. H. Huang (Eds.), Mo Yan in Context: Nobel Laureate and Global Storyteller (pp. 167-181). West Lafayette: Purdue UP.

Xi, J. P. (2016). Speech at the Symposium on the work of philosophy and Social Sciences. The Xinhua News Agency, 18(5). Retrieve from http://www.xinhuanet.com/politics/2016-05/18/c_1118891128.htm

Zhuang, P. N. (2014). Fill the Theoretical Gap in World Comparative Literature-A Review of Professor Cao Shuqing's The Variation Theory of Comparative Literature. Foreign Literature Studies, 3, 154-157.

https://www.amazon.com/s/ref=nb_sb_noss?url=search-alias\%3Daps\&field-keywords=variation+theory+ofa+co mparative+literature 
http://bookshop.blackwell.co.uk/bookshop/product/The-Variation-Theory-of-Comparative-Literature-by-Shunqin g-Cao/9783662523339

\section{Copyrights}

Copyright for this article is retained by the author, with first publication rights granted to the journal.

This is an open-access article distributed under the terms and conditions of the Creative Commons Attribution license (http://creativecommons.org/licenses/by/4.0/). 